\title{
Field Margins as Rapidly Evolving Local Diversity Hotspots for Ground Beetles (Coleoptera: Carabidae) in Northern China
}

\author{
ZHENRONG Yu AND Yunhui LiU \\ College of Agricultural Resources and Environmental Sciences \\ China Agricultural University, Beijing 100094, CHINA \\ liuyh@cau.edu.cn \\ AND \\ JAN C. AXMACHER \\ Department of Geography \\ University College London \\ 26 Bedford Way, London WC1H 0AP, U.K. \\ jan.axmacher@web.de
}

\begin{abstract}
The diversity of carabid assemblages at newly established field margins was compared to the diversity in surrounding fields and woodland habitats at Dongbeiwang village, Beijing. Carabids were sampled using 6 pitfalls per plot at a total of 12 plots in the year 2000. Although sampled only a year after their establishment, field margins harbored the most abundant and diverse carabids assemblages of all sites. More than a quarter of carabid species encountered were furthermore restricted to catches from field margins. Also woodland and fields under rotational wheat/maize cultivation harbored some unique species. Therefore, a short term establishment of field margins is effective in enhancing diversity and abundance of carabids, an important predator group in the agricultural landscape, while only the preservation of a heterogeneous landscape will enable the conservation of the overall species diversity.
\end{abstract}

Semi-natural habitats in agro-ecosystem such as woodland, hedges and especially field margins have been recognized for their importance in supporting a diverse fauna in the agricultural landscape (Lagerlöf and Wallin 1993; Douglas et al. 2002; Marshall and Moonen 2002). This is related to a great number of arthropods permanently living in these habitats (Kromp and Steinberger 1992; Thomas and Marshall 1999; Holland and Fahrig 2000), as well as to their role as over-wintering sites (MacLeod et al. 2004) and as dispersal corridors (Forman and Baudry 1984). While the importance of semi-natural habitats gets a lot of attention both by scientists and politicians (Thomas and Marshall 1999), little is known about the speed of colonization after their establishment.

In this study, species composition and diversity of ground beetles (Carabidae) is investigated at newly established field margins and compared to cereal and vegetable fields and to woodlands as an alternative type of semi-natural habitat. The study area at Dongbeiwang village close to Beijing has a long history of agricultural utilization, with only a few semi-natural habitats remaining. This, combined with the typically very high application rates of fertilizer and pesticides led to an overall low diversity level of local species pools. The central objective of this study was to investigate whether newly established field margins supported significantly more abundant and diverse assemblages of carabids than surrounding fields. As a second objective, carabids assemblages at fallow field margins were also compared to assemblages occurring at woodland habitats to evaluate the contribution of these two different habitats to the 
local species pool. Carabids were chosen as indicator taxon in this study as they are susceptible to standardized sampling via pitfall trapping, easy to preserve and to determine, and they react sensitively to changes of their environment (Thiele 1977). Furthermore, they are seen as an important predator group in agro-ecosystems (Lovei and Sunderland 1996; Kromp 1999).

\section{Materials and Methods}

This study was carried out in the framework of a Sino-German collaborative research project investigating "Environmentally compatible and sustainable agriculture on a high production level in the North China Plain." The study area was located at the experimental fields of the China Agricultural University at Dongbeiwang village, Beijing $\left(40.0^{\circ} \mathrm{N}, 116.2^{\circ} \mathrm{E}\right)$. Plots were established in three types of habitats: fields, fallow field margins and woodland. The woodland (WL) consisted of poplar trees (Populus tomentosa Carr.) planted as a wind-break more than ten years ago. The fallow field margin (FM) had formerly been part of a field with a rotating intensive cultivation of winter wheat and summer maize and bordered the woodland habitat. The fallow period started only in June 1999 less than a year before the beginning of the carabid sampling. Furthermore, two types of cropping systems were included in this study. At six fields winter wheat and summer maize (WM) were cultivated in rotation. This represents the most widespread cropping pattern for this region. At two more fields, three types of vegetables (VE) were produced in rotations with growing seasons for cauliflower ranging from $3^{\text {rd }}$ April to $6^{\text {th }}$ June, for amaranth from $1^{\text {st }}$ July to $28^{\text {th }}$ July and for spinach from $4^{\text {th }}$ September to $24^{\text {th }}$ October.

With regard to the agricultural management, four wheat-maize fields and one vegetable field were managed traditionally. The traditional management included $\mathrm{N}$ fertilizer applications of $300 \mathrm{~kg} \mathrm{ha}^{-1}$ and $117 \mathrm{~kg} \mathrm{ha}^{-1}$ of $\mathrm{P}_{2} \mathrm{O}_{5}$ for wheat and maize. At the vegetable field, $\mathrm{N}$ fertilization reached an overall amount of $889 \mathrm{~kg} \mathrm{ha}^{-1}$. The annual quantity of insecticides and herbicides applied to the fields added up to $1.5 \mathrm{~kg} \mathrm{ha}^{-1}$ and $15 \mathrm{~kg} \mathrm{ha}^{-1}$, respectively, for the wheat-maize cropping system. At the vegetable fields, weeds were removed manually. Furrow irrigation was used to irrigate the fields, with about $330 \mathrm{~mm}$ applied to the wheat-maize fields and-depending on the weather conditions-between 5 and $45 \mathrm{~mm}$ to each of the different vegetables. Fertilizer applications were reduced by about $15 \%$ on two additional wheat-maize fields and by about $20 \%$ on an additional vegetable field. At these fields, sprinklers were used instead of furrows for irrigation. Despite these differences in agricultural management, the resulting differences in the diversity of carabids assemblages were very small, and they are hence not further differentiated in this study.

Sampling of carabids occurred at one plot on each of the six wheat-maize fields and the two vegetable fields, and at two plots each situated in the newly established field margin and in the woodland. Pitfall traps partly filled with alcohol were used to preserve the catch (Southwood 1978). Six pitfalls were place along a straight line at $6 \mathrm{~m}$ intervals in the center of each plot. All traps were exposed for six days every month from May to October 2000. Altogether, catching was performed using 36 pitfall traps located in wheat-maize fields and 12 pitfall traps each set in the vegetable fields, at fallow field margins and the woodland, respectively. Samples were sorted and spread at the China Agricultural University and determined at the Institute of Zoology, China Academy of Sciences.

In order to compare the alpha-diversity of carabid assemblages occurring within the fallow field margin to that of assemblages in woodland and fields, rarefaction curves (Hurlbert 1971) were calculated for combined catches of each of these three habitat types using the program Species Diversity and Richness 3 (Henderson and Seaby 2002). Wheat-maize and vegetable fields were combined as the abundance of carabids 
at the vegetable fields was too low to analyze them separately. Two approaches were followed to analyze the similarity between the carabids assemblages occurring at the different plots. Similarity of ground beetle assemblages at the different plots and of the occurrence of single species were analyzed in a correspondence analysis. Furthermore, nonlinear multidimensional scaling (NMDS) of the chord-normalized expected species shared (CNESS) - index of dissimilarity (Trueblood et al. 1994) was calculated with the help of COMPAH (Gallagher 1998). By variation of the sample-size parameter $m$, the CNESS index of dissimilarity allowed a separate analysis with emphasis on the most dominant species $(m=1)$ and on rarer species $(m=12)$.

\section{Results}

A total of 1197 individuals, representing 30 species and 16 genera, were trapped at Dongbeiwang (Table 1). Among these, 11 species were represented by only one or two individuals, and a further 8 species occurred with less than 10 individuals in the catches. On the other hand, the 5 most common species accounted for more than $78 \%$ of all sampled individuals. Individuals of the genus Harpalus Latreille accounted for $77 \%$ of the catch and were common at all plots.

The rarefaction curves allowing a direct comparison of diversity levels for a given number of individuals (Fig. 1) clearly indicated that the highest diversity was encountered at the field margins, followed by the fields. The woodland habitat harbored a significantly lower diversity than the other two habitats.

Two-dimensional scaling of the CNESS index of dissimilarity for a minimum sample size parameter $m=1$ (Fig. 2) indicated that the dominance pattern of carabids species within the same semi-natural habitat type were very similar. Furthermore, woodland and field margin assemblages were clearly separated from each other along the second dimension and from the field assemblages along the first dimension. The assemblages at the fields were located further apart from each other in the ordination, hinting at a more heterogeneous pattern in the dominant species. For a larger sample size (Fig. 3), both assemblages within field margins and especially woodland were more dissimilar. In this ordination, the first dimension separated these plots from the field assemblages, which were also separated along this dimension into wheat/maize and vegetable fields.

In the ordination based on the correspondence analysis (Fig. 4), the first axis again separated assemblages at semi-natural habitats from wheat/maize fields and from vegetable fields. Woodland and field margin assemblages were separated along the second axis. For the distribution of carabids at the different plots, the beetles could clearly be divided into two groups along the first axis (Table 1). The first group consisted of the species only encountered within the field margin (Harpalus roninus Bates, H. jureceki (Jedlicka), H. tridens Morawitz, Oxycentrus argutoides (Bates), Chlaenius circumdatus Morawitz, Tachys sp., Anisodactylus signatus (Panzer), and Curtonotus gigantius Motschulsky), at woodland habitats (Badister marginellus Bates, Pterostichus gebleri Dejean, and Cymindis nirgrifemoris Habu \& Inouye) or at both these habitats (Curtonotus macronota Sols, and Dolichus halensis Schaller). The species restricted to only one semi-natural habitat were identical to the species occurring with only one or two individuals in the catches. Six further species (Harpalus pastor Motschulsky, H. griseus (Panzer), H. pallidipennis Morawitz, H. simplicidens Schauberger, H. sinicus Hope and Microlestes minitulus (Goeze)) with a clear preference to semi-natural habitats with less than one quarter of all individuals encountered within the fields also belonged to this first group. Among these six species were the four most common species in the study area $(H$. pastor, $H$. griseus, $H$. simplicidens and $H$. sinicus). The second group consisted of the three species restricted to the traditionally managed wheat/maize fields (Calosoma chinense Kirby, Harpalus 
Table 1. Individuals of carabid species trapped at different sites. Species are sorted according to their occurrence at the different treatments as described in the text.

\begin{tabular}{|c|c|c|c|c|c|c|c|c|c|c|c|c|c|}
\hline & Species & FM1 & FM2 & WL1 & WL2 & WM1 & WM2 & WM3 & WM4 & WM5 & WM6 & VE1 & VE2 \\
\hline S1 & $\begin{array}{l}\text { Harpalus } \\
\text { roninus Bates }\end{array}$ & 1 & - & - & - & - & - & - & - & - & - & - & - \\
\hline S2 & $\begin{array}{l}\text { Oxycentrus } \\
\quad \text { argutoides (Bates) }\end{array}$ & 1 & - & - & - & - & - & - & - & - & - & - & - \\
\hline S3 & $\begin{array}{l}\text { Chlaenius } \\
\text { circumdatus Morawitz }\end{array}$ & - & 1 & - & - & - & - & - & - & - & - & - & - \\
\hline S4 & $\begin{array}{l}\text { Harpalus } \\
\quad \text { jureceki (Jedlicka) }\end{array}$ & - & 1 & - & - & - & - & - & - & - & - & - & - \\
\hline S5 & Tackys sp. & - & 1 & - & - & - & - & - & - & - & - & - & - \\
\hline S6 & $\begin{array}{l}\text { Anisodactylus } \\
\text { signatus (Panzer) }\end{array}$ & - & 1 & - & - & - & - & - & - & - & - & - & - \\
\hline S7 & $\begin{array}{l}\text { Curtonotus } \\
\text { giganteus } \text { Motschulsky }\end{array}$ & 2 & - & - & - & - & - & - & - & - & - & - & - \\
\hline S8 & $\begin{array}{l}\text { Harpalus } \\
\text { tridens } \text { Morawitz }\end{array}$ & - & 2 & - & - & - & - & - & - & - & - & - & - \\
\hline S9 & $\begin{array}{l}\text { Badister } \\
\quad \text { marginellus Bates }\end{array}$ & - & - & 1 & - & - & - & - & - & - & - & - & - \\
\hline S10 & $\begin{array}{l}\text { Pterostichus } \\
\quad \text { gebleri Dejean }\end{array}$ & - & - & 1 & - & - & - & - & - & - & - & - & - \\
\hline S11 & $\begin{array}{l}\text { Cymindis nigrifemoris } \\
\text { Habu \& Inouye }\end{array}$ & - & - & - & 1 & - & - & - & - & - & - & - & - \\
\hline S12 & $\begin{array}{l}\text { Curtonotus } \\
\quad \text { macronota Sols }\end{array}$ & - & 4 & 3 & 2 & - & - & - & - & - & - & - & - \\
\hline S13 & $\begin{array}{l}\text { Dolichus halensis } \\
\text { Schaller }\end{array}$ & 9 & 9 & 9 & 3 & - & - & - & - & - & - & - & - \\
\hline S14 & $\begin{array}{l}\text { Harpalus pastor } \\
\text { Motschulsky }\end{array}$ & 36 & 53 & 126 & 43 & - & - & 6 & 33 & 2 & 2 & - & - \\
\hline S15 & $\begin{array}{l}\text { Harpalus griseus } \\
\text { (Panzer) }\end{array}$ & 37 & 63 & 65 & 23 & 8 & 1 & 10 & 28 & 6 & 6 & - & - \\
\hline S16 & $\begin{array}{l}\text { Harpalus pallidipennis } \\
\text { Morawitz }\end{array}$ & 7 & 11 & 12 & 11 & 3 & 1 & 1 & 4 & - & - & 3 & - \\
\hline S17 & $\begin{array}{l}\text { Microlestes } \\
\text { minitulus (Goeze) }\end{array}$ & 1 & - & 4 & - & 1 & - & - & - & - & - & - & - \\
\hline S18 & $\begin{array}{l}\text { Harpalus }(p .) \\
\text { simplicidens } \\
\text { Schauberger }\end{array}$ & 69 & 87 & 10 & 3 & 1 & - & 3 & 7 & - & 1 & - & - \\
\hline S19 & Harpalus & 23 & 75 & 2 & 3 & 1 & - & 5 & 16 & 1 & - & - & - \\
\hline $\mathrm{S} 20$ & Calo & - & - & - & - & 1 & - & - & 2 & - & - & - & - \\
\hline S21 & $\begin{array}{l}\text { Harpalus bungii } \\
\text { Chaudoir }\end{array}$ & - & - & - & - & - & - & 1 & 2 & - & - & - & - \\
\hline S22 & Harpalus chalent & - & - & - & - & - & - & 1 & 2 & - & - & - & - \\
\hline S23 & $\begin{array}{l}\text { Asaphidion angulicelle } \\
\text { Morawitz }\end{array}$ & - & - & 2 & - & - & - & - & - & - & 2 & - & 2 \\
\hline S24 & $\begin{array}{l}\text { Chlaenius posticalis } \\
\text { Motschulsky }\end{array}$ & 3 & - & - & - & - & - & 2 & 4 & - & - & - & - \\
\hline S2: & Scarit & 2 & 3 & - & - & - & - & 1 & 2 & 1 & - & 2 & - \\
\hline S26 & $\begin{array}{l}\text { Pterostichus microcephalus } \\
\text { Motschulsky }\end{array}$ & 2 & - & - & - & 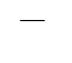 & 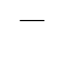 & 1 & 8 & & - & 1 & 4 \\
\hline S27 & Tachys gradatus Bates & 2 & 2 & - & 1 & 2 & 1 & 10 & 30 & 1 & 2 & 7 & 3 \\
\hline $\mathrm{S} 28$ & Dyschirius s & 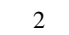 & 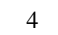 & 2 & 2 & - & 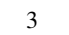 & 2 & 10 & 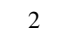 & 1 & 2 & - \\
\hline S29 & $\begin{array}{l}\text { Chlaenius micans } \\
\text { Fabricius }\end{array}$ & 15 & 11 & 1 & 2 & 10 & 8 & 4 & 12 & 12 & 6 & - & 3 \\
\hline S30 & $\begin{array}{l}\text { Lesticus magnus } \\
\text { Motschulsky }\end{array}$ & 1 & 2 & - & - & - & - & - & - & - & - & 2 & - \\
\hline
\end{tabular}

FM: fallow field margin, WL: Woodland, WM: wheat/maize field, VE: vegetable field. 


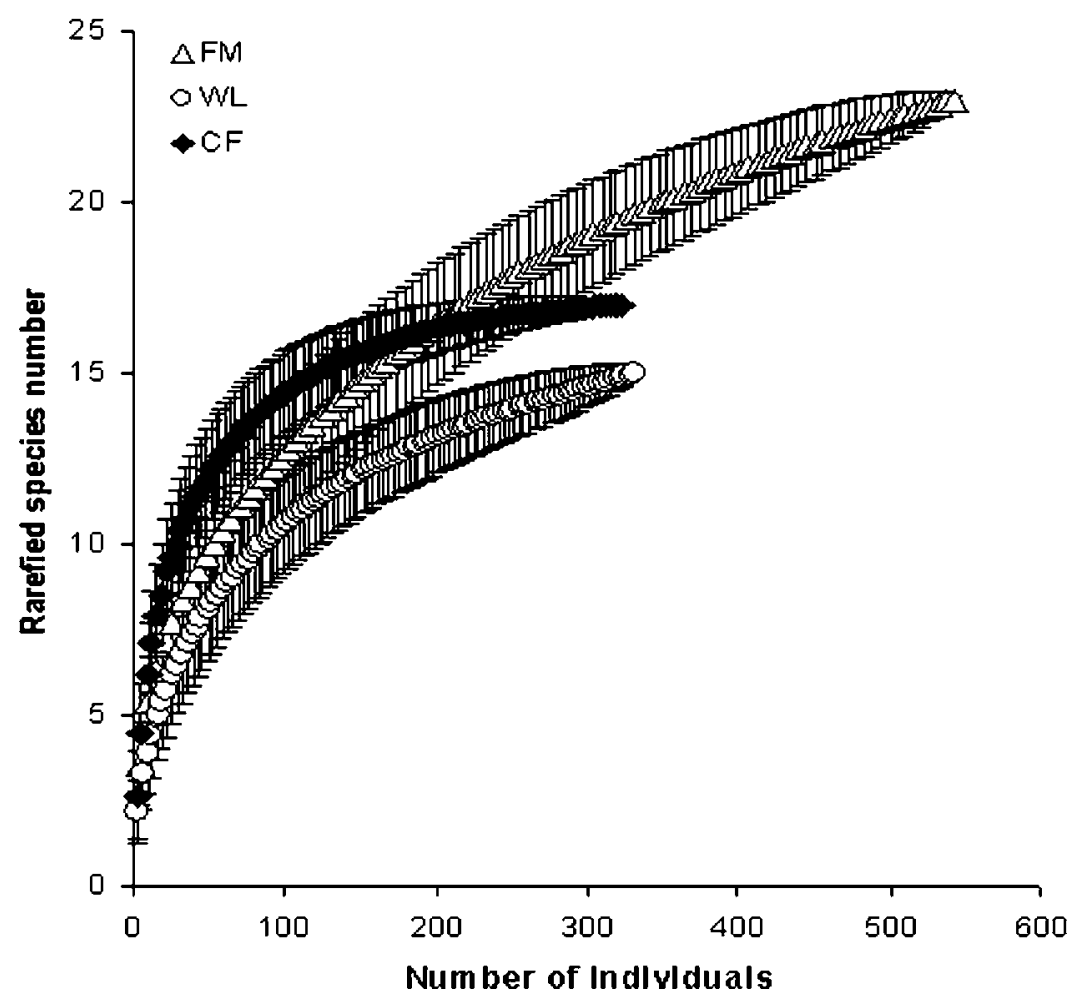

Fig. 1. Hurlbert rarefaction curves for the combined catches at different treatments (FM: fallow field margin, WL: woodland, CF: combined catches from all fields). Bars indicate the standard error.

bungii Caudoir and $H$. chalentus Bates) as well as of 7 species with the majority of individuals encountered on the fields (Asaphidion angulicolle Morawitz, Chlaenius posticalis Motschulsky, C. micans Fabricius, Scarites terricola Bonelli, Pterostichus microcephalus Motschulsky, Tachys gradates Bates and Dyschirius sp.). Finally, one species (Lesticus magnus Motschulsky) encountered with 1-2 individuals both at vegetable fields and field margins was contained in this group.

\section{Discussion}

A first major outcome of this study is the fact that already a year after their establishment, field margins harbored a much higher diversity of ground beetles than surrounding fields, but especially than woodland habitats, which showed an even lower diversity of ground beetles than the combined fields. Nevertheless, plots at woodland and fallow margins showed a much higher overall abundance of carabids, with sampling at two plots for each treatment already yielding a higher number of beetles than that at 8 plots in the fields combined.

The high carabids diversity encountered at the fallow margin raised the question where the respective species originated from. A joined analysis of the distribution pattern of the carabid species (Table 1) and the ordinations allowed some insights. Species occurring at the fallow margin may generally be divided into three groups. A first group consisting of 6 species caught in the newly established fallow field margin 


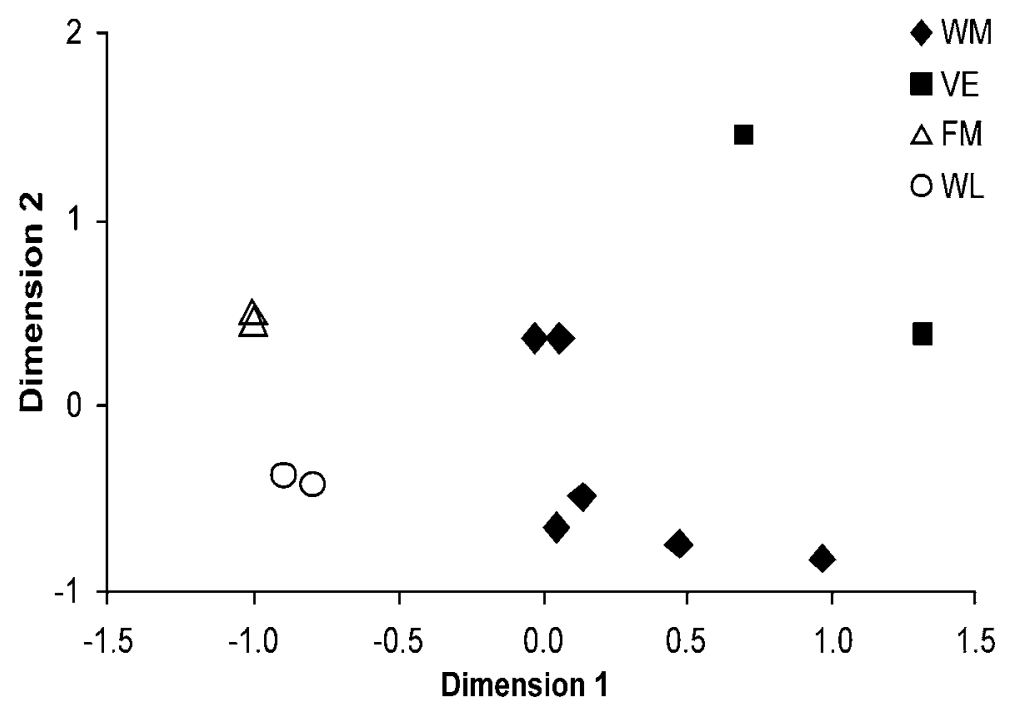

Fig. 2. Non-linear two-dimensional scaling of carabid samples based on the CNESS index of dissimilarity for a minimum samples size $(m=1$; stress $=0.08$; FM: fallow field margin, WL: woodland, WM: wheat/maize field, VE: vegetable field).

most probably originated from the neighboring woodland strip. Such a colonization can be presumed for the two rare species restricted to these two semi-natural habitats (C. macronota, D. halensis), but also for the four species (H. pastor, H. griseus, $H$. pallidipennis, $M$. minitulus) occurring with by far the highest numbers encountered in the woodland habitat. A second group consisted of 9 species (H. simplicidens, $H$. sinicus, C. posticalis, C. micans, S. terricola, P. microcephalus, T. gradates, L. magnus, Dyschirius sp.) which all were regularly encountered within the fields. For these species, the fields might therefore have been a source for the colonization of the field margin - or they might also simply have persisted after the start of the fallow period. A short-distance colonization of neighboring habitats is well documented in the literature (French et al. 2001; Bommarco and Fagan 2002). Nevertheless, at least a third of the species occurring at the field margin (A. signatus, H. roninus, H. jureceki, $H$. tridens, $C$. circumdatus, $C$. giganteus, $O$. argutoides, Tackys sp.) were exclusively caught there, all also being rare species. Although it cannot be completely ruled out that these rare species also occurred at the other habitats and had been missed in the respective catches, it seems highly probable that some of these species also colonized the fallow margin from outside the study area. This showed on one hand that at least parts of the regional species pool of carabids had a strong ability for long-distance dispersal. Furthermore, the speed with which new species discovered and inhabited the newly established field margin showed that these carabid beetles must be considered as extremely mobile. Nevertheless, the very low diversity of carabids assemblages from agricultural areas with a very similar agricultural management pattern about $450 \mathrm{~km}$ south of Beijing in Quzhou county (Liu et al. 2006) shows that this dispersal ability is somewhat limited for very long distances.

With regard to the structure of the carabid communities, both field margin and woodland assemblages were dominated by Harpalus spp. with $H$. pastor dominating at both woodland plots and $H$. simplicidens at both margins, resulting in near-identical 


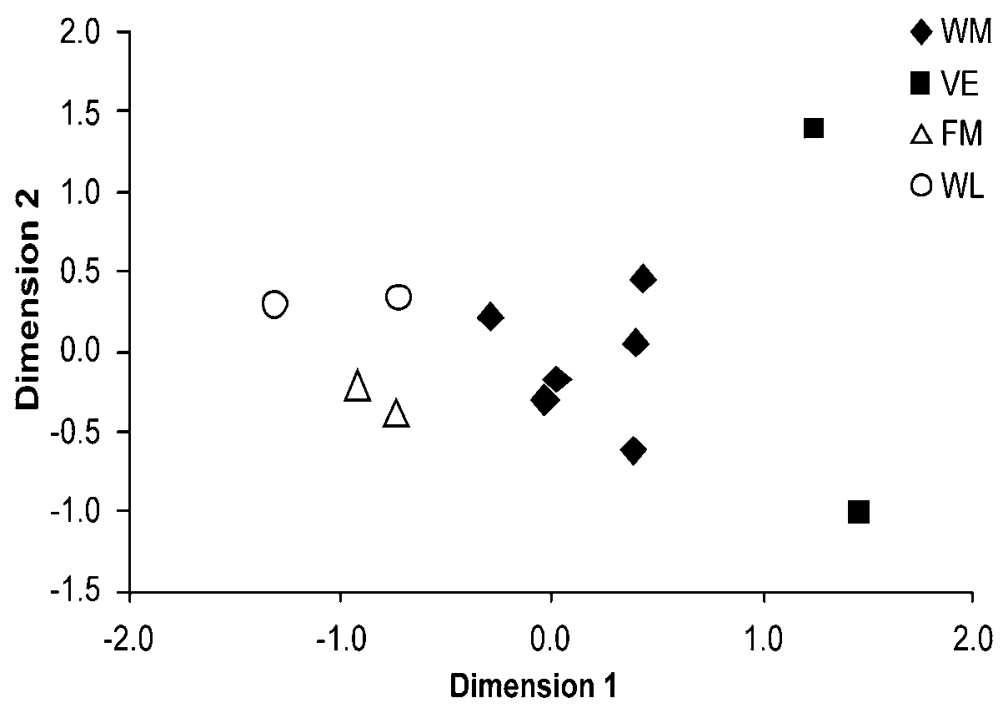

Fig. 3. Non-linear two-dimensional scaling of carabid samples based on the CNESS index of dissimilarity for a maximum samples size $(m=12$; stress $=0.10$; FM: fallow field margin, WL: woodland, WM: wheat/maize field, VE: vegetable field).

positions of the parallels in the NMDS for a low value of $m$ as well as in the correspondence analysis. For the fields with an overall small number of species compared to the semi-natural habitats, the dominant species varied from site to site, which was reflected in their widespread distribution in the ordinations. The ordination with a maximum $m$ putting a larger emphasis on less common species again showed a great similarity of the composition within the field margin, whereas woodland, wheat/ maize fields and especially the vegetable fields proved to be dissimilar.

Generally, these results may not seem surprising, as carabids have been well known to react sensitively to differing intensities of agricultural management (Thiele 1977; Kromp 1989, 1990; Andersen and Eltun 2000; Shah et al. 2003). More surprising was the speed and extent to which these changes occurred, with more than a third of all species encountered in this study restricted to the newly established field margin.

\section{Conclusion}

The results strongly suggest that a cost- and labor-efficient establishment of even temporary strips of fallow land might be a powerful tool to enhance both the diversity and the abundance of carabid beetles in the agricultural landscape, which in terms might help in the biological control of pest insects and weeds by these partly predatory, partly granivorous insects.

Nevertheless, it also has to be taken into account that not only samples from field margins, but also from woodland-and even from within the wheat/maize fieldyielded unique species. The latter obviously adapt to the agricultural management over the long history of cereal cultivation occurring in the area, a phenomenon also observed in other parts of the world (Wallin 1988; Kromp and Steinberger 1992). For the overall conservation of the ground beetle diversity in the landscape around Beijing, the 


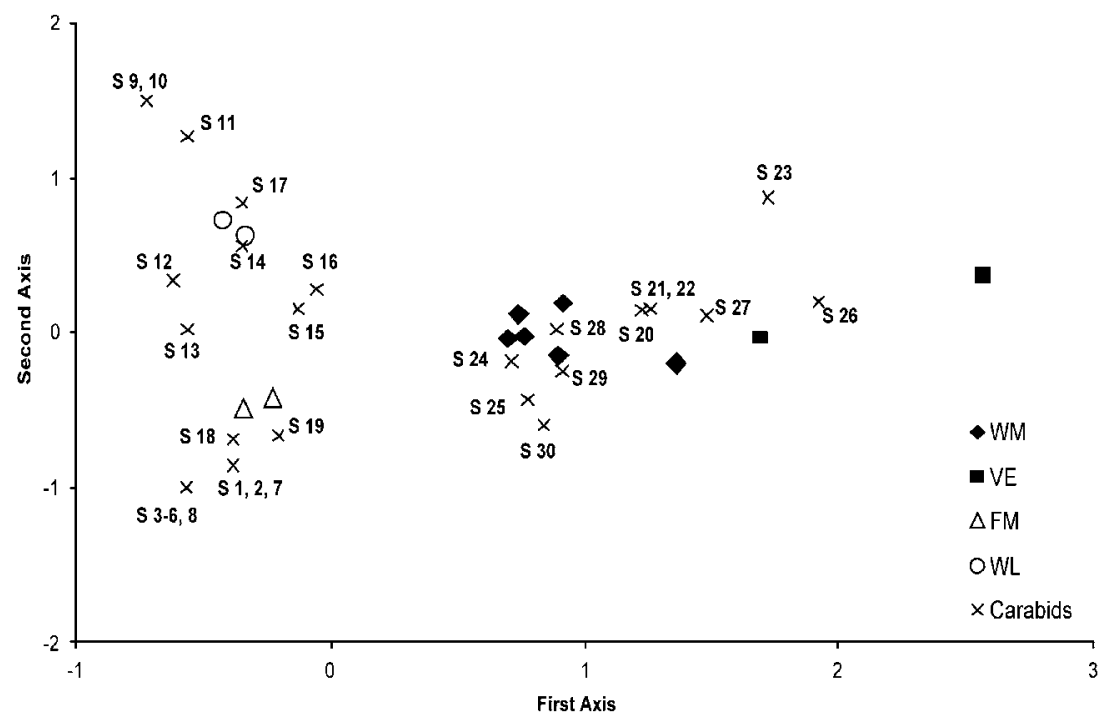

Fig. 4. Ordination of the different carabids assemblages based on the correspondence analysis (FM: fallow field margin, WL: woodland, WM: wheat/maize field, VE: vegetable field, crosses and text refers to the different carabids species listed in Table 1).

preservation of the heterogeneous landscape must therefore be seen as the most appropriate measure.

\section{Acknowledgments}

The authors are greatly indebted to the Natural Science Foundation of China (30570318), the Deutsche Forschungsgemeinschaft (GRK 1070), the Chinese Ministry of Education (985) as well as the German Federal Ministry of Education and Research (0339712A/9) for their financial support. We are very grateful to Dr. Liang Hongbin from the Institute of Zoology, China Academy of Sciences, for his great help with the determination of carabid specimens. We also like to thank two unknown referees for their constructive and helpful comments on earlier versions of the manuscript.

\section{Literature Cited}

Andersen, A., and R. Eltun. 2000. Long-term developments in the carabid and staphylinid (Col., Carabidae and Staphylinidae) fauna during conversion from conventional to biological farming. Journal of Applied Entomology 124:51-56.

Bommarco, R., and W. F. Fagan. 2002. Influence of crop edges on movement of generalist predators: a diffusion approach. Agricultural and Forest Entomology 4:21-30.

Douglas, A. L., D. W. Stephen, and M. G. Geoff. 2002. Habitat management to conserve natural enemies of arthropod pests in agriculture. Annual Review of Entomology 45:175-201.

Forman, R. T. T., and J. Baudry. 1984. Hedgerows and hedgerow networks in landscape ecology. Environmental Management 8:495-510.

French, B. W., N. C. Elliott, R. C. Berberet, and J. D. Burd. 2001. Effects of riparian and grassland habitats on ground beetle (Coleoptera: Carabidae) assemblages in adjacent wheat fields. Community and Ecosystem Ecology 30:225-234.

Gallagher, E. D. 1998. Compah96. http://www.es.umb.edu/faculty/edg/files/pub/COMPAH.EXE (accessed 24 September 2004). 
Henderson, P. A., and R. M. H. Seaby. 2002. Species diversity and richness 3. Pisces Conservation Ltd., Pennington.

Holland, J., and L. Fahrig. 2000. Effect of wood borders on insect density and diversity in crop fields: a Landscape-scale analysis. Agriculture Ecosystem \& Environment 78:115-122.

Hurlbert, S. H. 1971. The nonconcept of species diversity: a critique and alternative parameters. Ecology 52:577-586.

Kromp, B. 1989. Carabid beetle communities (Carabidae, Coleoptera) in biologically and conventionally farmed agroecosystems. Agriculture, Ecosystems \& Environment 27: 241-251.

Kromp, B. 1990. Carabid beetles (Coleoptera, Carabidae) as bioindicators in biological and conventional farming in Austrian potato fields. Biology and Fertility of Soil 9:182-187.

Kromp, B. 1999. Carabid beetles in sustainable agriculture: a review on pest control efficacy, cultivation impacts and enhancement. Agriculture, Ecosystems \& Environment 74: $187-228$.

Kromp, B., and K. H. Steinberger. 1992. Grassy field margins and arthropod diversity: a case study on ground beetles and spiders in eastern Austria (Coleoptera: Carabidae; Arachnida: Aranei, Opiliones). Agriculture, Ecosystems \& Environment 40:71-93.

Lagerlöf, J., and H. Wallin. 1993. The abundance of arthropods along two field margins with different types of vegetation composition: an experimental study. Agriculture, Ecosystems \& Environment 43:141-154.

Liu, Y. H., Z. R. Yu, W. B. Gu, and J. C. Axmacher. 2006. Diversity of carabids (Coleoptera, Carabidae) in the desalinized agricultural landscape of Quzhou county, China. Agriculture, Ecosystems \& Environment 113:45-50.

Lovei, G. L., and K. D. Sunderland. 1996. Ecology and behavior of ground beetles (Coleoptera: Carabidae). Annual Review of Entomology 41:231-256.

MacLeod, A., S. D. Wratten, N. W. Sotherton, and M. B. Thomas. 2004. 'Beetle banks' as refuges for beneficial arthropods in farmland: Long-term changes in predator communities and habitat. Agricultural and Forest Entomology 6:147-154.

Marshall, E. J. P., and A. C. Moonen. 2002. Field margins in northern Europe: their functions and interactions with agriculture. Agriculture, Ecosystems \& Environment 89:5-21.

Shah, P. A., D. R. Brooks, J. E. Ashby, J. N. Perry, and I. P. Woiwod. 2003. Diversity and abundance of the coleopteran fauna from organic and conventional management systems in southern England. Agricultural and Forest Entomology 5:51-60.

Southwood, T. R. E. 1978. Ecological methods. Chapman and Hall, London. 524 pp.

Thiele, H. U. 1977. Carabid Beetles in their environments-a study on habitat selection by adaptations in physiology and behavior. Springer-Verlag, Berlin. 369 pp.

Thomas, C. F. G., and E. J. P. Marshall. 1999. Arthropod abundance and diversity in differently vegetated margins of arable fields. Agriculture, Ecosystems \& Environment 72:131-144.

Trueblood, D. D., E. D. Gallagher, and D. M. Gould. 1994. The three stages of seasonal succession on the Savin Hill Cove mudflat, Boston Harbour. Limnology and Oceanography 39:1440-1454.

Wallin, H. 1988. The effects of spatial distribution on the development and reproduction of Pterostichus cupreus L., P. melanarius Ill., P. niger Schal. and Harpalus rufipes deGeer (Col., Carabidae) on arable land. Journal of Applied Entomology 106:483-487.

(Received 17 August 2005; accepted 12 March 2006. Publication date 19 July 2006.) 